\title{
HIV-related knowledge and perceptions by academic major: implications for university interventions
}

\author{
Matthew Lee Smith ${ }^{1,2}$ *, Lisa L. La Place ${ }^{1}$, Mindy Menn ${ }^{3}$ and Kelly L. Wilson ${ }^{4}$ \\ 1 Department of Health Promotion and Behavior, College of Public Health, University of Georgia, Athens, GA, USA \\ ${ }^{2}$ Department of Social and Behavioral Health, School of Rural Public Health, Texas A\&M Health Science Center, College Station, TX, USA \\ ${ }^{3}$ College of Health and Human Performance, University of Florida, Gainesville, FL, USA \\ ${ }^{4}$ Department of Health and Kinesiology, Texas A\&M University, College Station, TX, USA
}

Edited by:

Roger A. Harrison, University of Manchester, UK

Reviewed by:

Michelle D. Bell, Harvard School of

Public Health, USA

Judith Clegg, University of

Manchester, UK

*Correspondence:

Matthew Lee Smith, Department of

Health Promotion and Behavior,

College of Public Health, University of

Georgia, 330 River Road, 315 Ramsey

Center, Athens, GA 30602, USA

e-mail:health@uga.edu
Most universities offer human sexuality courses, although they are not required for graduation. While students in health-related majors may receive sexuality education in formal settings, majority of college students never receive formal sexual health or HIV/AIDSrelated education, which may lead to elevated engagement in high-risk sexual behaviors. This study examines perceived knowledge about HIV/AIDS, perceived risk, and perceived consequences among college students by two distinct classifications of academic majors. Data were collected from 510 college students. Binary and multinomial logistic regressions were performed to compare HIV-related covariates by academic major category. Limited differences were observed by science, technology, engineering, and mathematics categorization. Relative to health and kinesiology majors, those who self-reported being "completely knowledgeable" about HIV were less likely to be physical sciences, mathematics, engineering, and business (PMEB) $(O R=0.41, P=0.047)$ or education, humanities, and social sciences majors ( $O R=0.25, P=0.004)$. PMEB majors were less likely to report behavioral factors as a risk for contracting HIV $(\mathrm{OR}=0.86, P=0.004)$ and perceived acquiring HIV would be more detrimental to their quality of life $(O R=2.14, P=0.012)$, but less detrimental to their mental well-being $(\mathrm{OR}=0.58, P=0.042)$. Findings can inform collegewide campaigns and interventions to raise HIVIAIDS awareness and improve college health.

Keywords: HIV, AIDS, college students, academic major, perceived risk

\section{INTRODUCTION}

The traditional college years represent a well-documented period of marked identity development and exploration both in and out of the classroom. As a facet of student development outside of the classroom, extracurricular experimentation with one's sexual identity (with new sexual partners and with new sexual behaviors) is pervasive in the American college culture and spans across majors (1). Recently, many authors documented undergraduate students' self-reported engagement in risky sexual behaviors such as engaging in sex while drunk, engaging in sex with multiple partners, and engaging in unprotected sex (2-6). These behaviors carry inherent and varied risks of HIV transmission, yet the American College Health Association's National College Health Assessment (ACHA-NCHA) revealed a majority of students surveyed had never been tested for HIV $(n=17,166 ; 73.4 \%)$ and were not interested in receiving sexually transmitted disease prevention information from their institution $(n=14,823 ; 63.7 \%)$.

Within the classroom and the broader academic realm of higher education, students and university personnel are concerned with a student's academic field of study or "major" since the selection, progression, and completion of a degree program are hallmarks of the university experience $(5,7-11)$. The major is prevalent in the American higher education system and provides benefits for students and for institutions. For students, the major provides a predetermined plan of study; varying in flexibility between departments, fields, and institutions. The major is the framework for prescribing coursework selected by scholars in the field, and approved by the degree-granting institution. Selecting a college major signals the beginning of a journey toward developing competence regarding a specific subject and narrowing career options to those that meet the students' interests and abilities honed through major coursework. For institutions, majors provide a consistent basis to classify, group, and divide students, faculty, physical, and financial resources.

Though every institution's leaders have varied freedom to group majors into colleges, departments, or schools for organizational purposes, an emerging method of demarcating and dichotomizing majors is the use of the science, technology, engineering, and mathematics (STEM) categorization. Though a universal definition of STEM or list of STEM majors does not exist (12), the United States Immigration and Customs Enforcement (an agency operating within the Department of Homeland Security) publishes a STEM degree program list that it uses to classify college majors as STEM or Non-STEM. This designation is then used to grant or deny foreign-born college graduates optional practical training work permits. 
Within the last decade, initiatives from the National Science Foundation, the White House, National Academies, and the United States Department of Education increased funding for programs to increase students' interest, enrollment, and completion of STEM degrees; further cementing the dichotomy of STEM and nonSTEM majors. As a natural result of this increased funding, dichotomization, and attention, numerous authors have compared STEM and non-STEM majors regarding enrollment, persistence, and graduation rates (13-17). Conversely, no identified researchers have explored the relationship between students' majors and perceptions of HIV; therefore the purposes of this study were to: (1) identify participant's perceived knowledge about HIV/AIDS, perceived risk, and perceived consequences among college students; and (2) examine how these factors differ by academic major. Recognizing that students in certain fields of study are exposed to more health protective information than students in other disciplines, the authors hypothesized that health and kinesiology (HK) majors would self-report higher levels of knowledge regarding HIV/AIDS and have more accurate perceptions of HIV-related risk factors and consequences than students in other majors.

\section{MATERIALS AND METHODS}

The "Finding Roots: Exploring Your Family History" study examined college students' knowledge and perceptions regarding family health history and chronic diseases (i.e., HIV/AIDS, cancer, heart disease, diabetes, cystic fibrosis, and being overweight or obese) (18-21). The survey was developed based on the health belief model (22) and consisted of 60 items; included Likert-type scales, checklists, and close-ended response formats. The 60 items addressed investigators' primary interest areas including: communication about family history and disease among family members, perceptions of severity and incidence regarding several common chronic diseases, perceived causes of diseases, perceived consequences of getting the disease, and a battery of items pertaining to the participants' sociodemographics. Additional information about the survey instrument is available upon request to the corresponding author.

The survey was disseminated online through course listserv without attached course credit or extra credit and 703 students voluntarily responded. Institutional Review Board approval was received for this study, which oversees the ethical and professional standards of research involving human subjects. Of the 703 survey participants, those who indicated they had been diagnosed with HIV $(n=5)$, knew someone diagnosed with HIV $(n=69)$, and were enrolled in graduate school $(n=66)$ were omitted from analyses to reduce bias concerning HIV/AIDS-related knowledge level and risk perception. Further, participants who did not report their academic major were excluded from this study $(n=54)$. Thus, the resulting analytic sample consisted of 510 undergraduate students.

\section{MEASURES}

\section{Dependent variable: primary and secondary majors}

Two classification levels of college students' self-reported academic majors were used as dependent variables for this study. Academic majors were primarily dichotomized into STEM and non-STEM categories. Then, the authors segmented all reported academic majors into four secondary classification groups based on common nature, associated skill sets, and professional philosophies. The four secondary academic major groups included: (1) physical sciences, mathematics, engineering, and business (PMEB); (2) education, humanities, and social sciences (EHS); (3) biological sciences (BS); and (4) HK. Table 1 presents the primary and secondary academic major categories used for analyses in this study.

\section{HIV/AIDS knowledge and risk perceptions}

Variables used to identify college students' perceptions about HIV/AIDS included: self-rated HIV/AIDS knowledge (i.e., if the participant had no/low knowledge, was somewhat knowledgeable, was completely knowledgeable); and susceptibility of contracting HIV in their lifetime (i.e., if the participant perceived to have no chance of contracting HIV, be unlikely to contract HIV, be likely to contract HIV).

\section{Factors influencing HIV transmission}

Participants ranked their beliefs about the extent to which five factor types attributed to an individual contracting HIV (i.e., behavioral, social, genetic, environmental, and spiritual). Participants were asked, "On a scale from 1 to 10 , how much do (blank) factors influence your likelihood to develop HIV?" Higher scores indicated the participant believed that factor had more influence on an individual contracting HIV. Responses for each of these five items were recorded independently and treated as continuous variables.

\section{Consequences of HIV}

Participants ranked their beliefs about the extent to which six aspects of their life would be impacted if they were to contract HIV (i.e., quality of life, physical well-being, mental well-being, social life, emotional well-being, spiritual well-being). Participants were asked, "On a scale from 1 to 7 , how detrimental would having HIV be to your___ ? Higher scores indicated the participant believed having HIV would be more detrimental to that aspect of their life. Responses for each of these six items were recorded independently and treated as continuous variables.

\section{Personal characteristics}

Personal characteristics of the participants included: age group (i.e., 18, 19, 20 years, between ages 21 and 24 years); sex; and race/ethnicity (i.e., non-Hispanic white, racial/ethnic minority).

\section{DATA ANALYSIS}

All statistical analyses were performed using SPSS (version 17). Frequencies were calculated for all categorical study variables, which were initially examined in relationship to the primary and secondary academic major categories. Pearson's chi-square tests were performed to assess the independence between the dependent variable and categorized independent variables. Independent sample $t$-tests and one-way ANOVA was used to evaluate the mean differences among academic major categories for continuous variables. Bonferroni post hoc analyses were performed to identify the origins of significant mean differences. Binary logistic regression was used to identify personal characteristics, self-reported HIV 


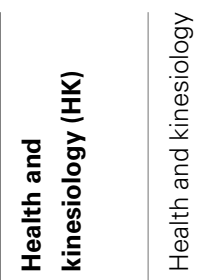

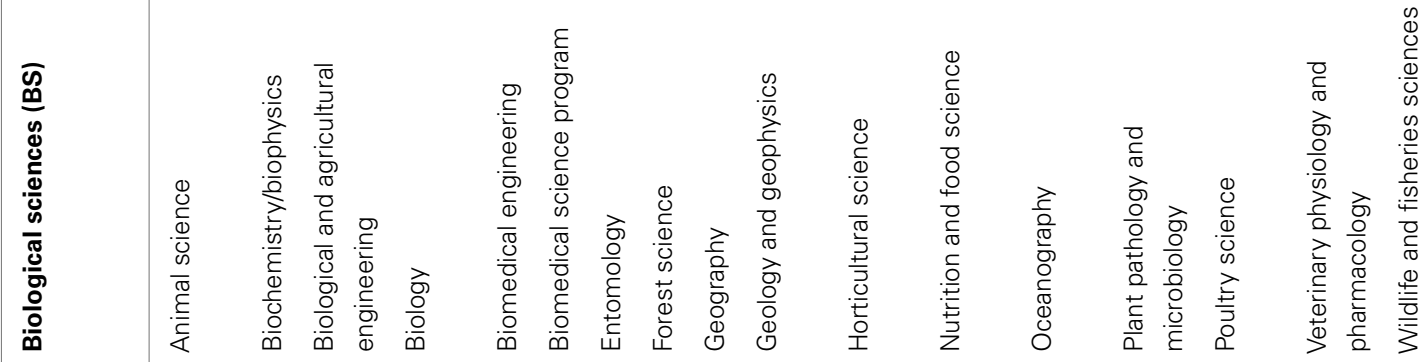
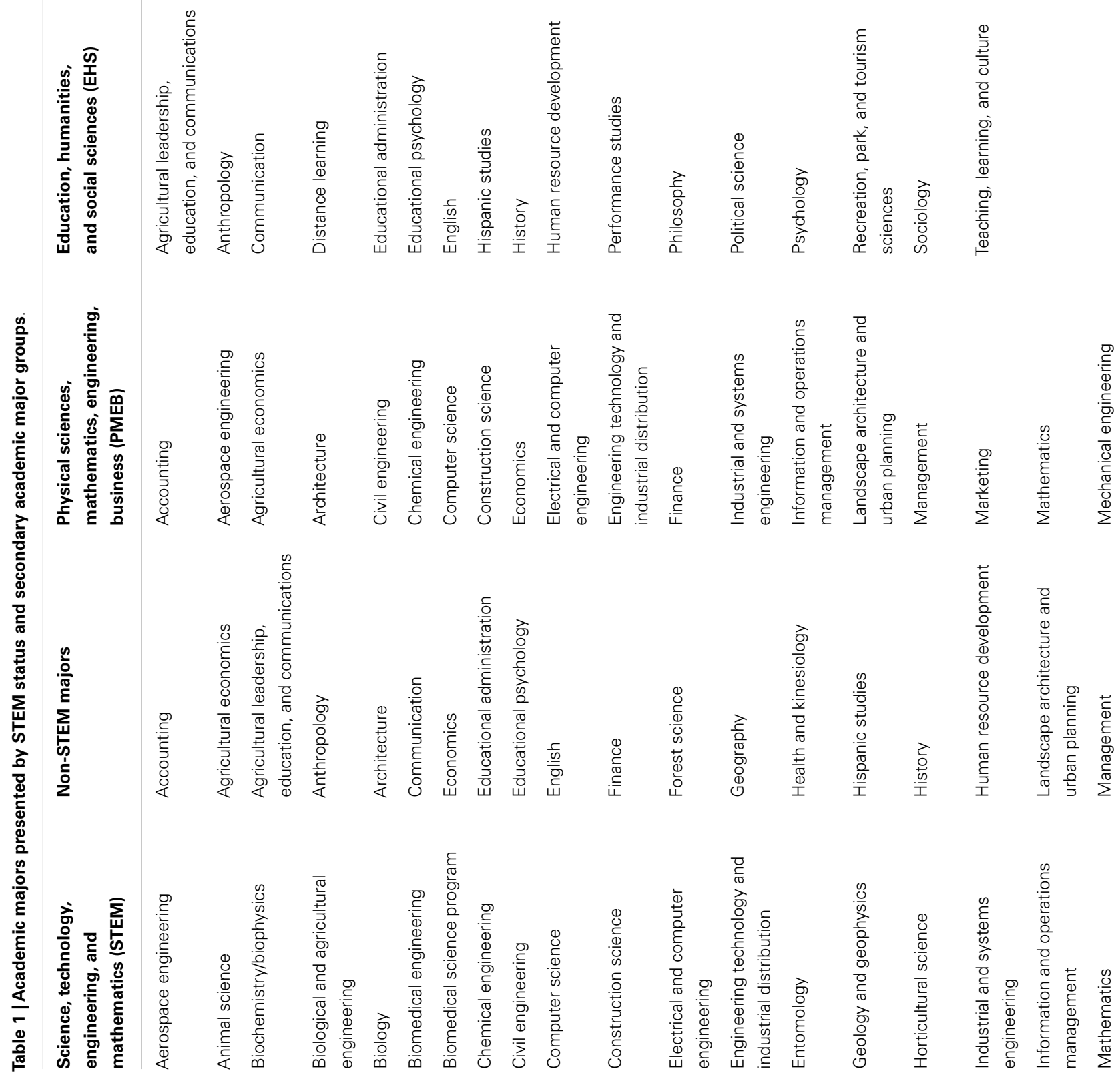


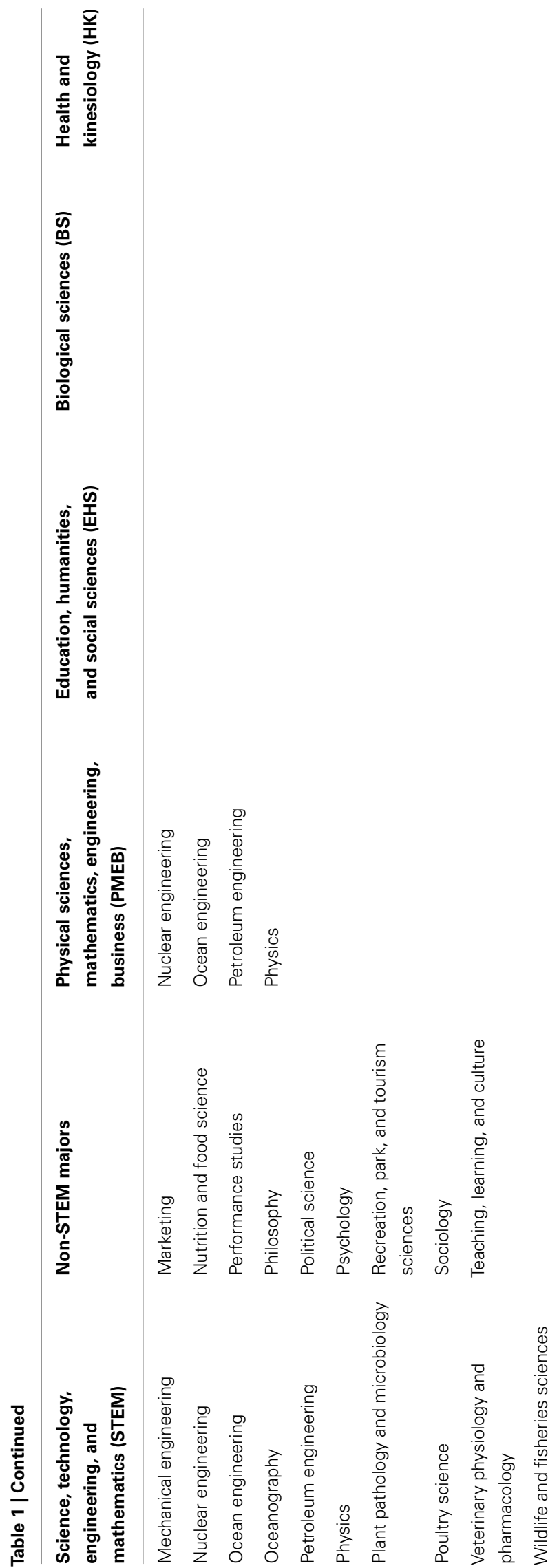

knowledge, factors believed to influence HIV transmission, and perceived consequences of HIV associated with participants' academic majors by STEM status (i.e., the non-STEM category served as the referent group). Multinomial logistic regression was used to identify associations among these factors with participants' secondary academic major groups (i.e., the HK category served as the referent group).

\section{RESULTS}

\section{SAMPLE CHARACTERISTICS}

Participants' personal characteristics, self-reported HIV-related knowledge, and perceived risk for contracting HIV are presented in Table 2. Of these 510 undergraduate college students, $41.6 \%$ were enrolled in majors categorized as STEM majors and in regard to the secondary academic major groups, $28.2 \%$ were PMEB majors, $22.6 \%$ were EHS majors, $24.3 \%$ were BS majors, and $24.9 \%$ were HK majors. The majority of participants were $20-24$ years of age $(67.9 \%)$, female $(62.4 \%)$, and non-Hispanic white $(74.3 \%)$. Approximately one-quarter of participants selfreported having no/low levels of HIV/AIDS-related knowledge, compared to $55.7 \%$ who reported being somewhat knowledgeable, and $19.0 \%$ who reported being completely knowledgeable. The majority of students reported having no chance of contracting HIV in their lifetime (57.3\%) and approximately $10 \%$ of participants reported they were likely to contract HIV in their lifetime.

When comparing characteristics by the academic major categories, statistically significant differences were observed. A significantly larger proportion of STEM majors were in younger age groups $\left(\chi^{2}=18.43, P<0.001\right)$; whereas, a significantly smaller proportion of STEM majors were female $\left(\chi^{2}=79.86, P<0.001\right)$ in comparison to their non-STEM counterparts. In terms of secondary academic major groups, larger proportions of PMEB and BS majors were in younger age groups relative to EHS and HK majors $\left(\chi^{2}=38.46, P<0.001\right)$. A significantly smaller proportion of PMEB majors $(30.0 \%)$ were female compared to those in other majors (ranging from 66.7 to $87.4 \%)\left(\chi^{2}=114.81\right.$, $P<0.001)$. Significantly larger proportions of PMEB $(30.0 \%)$ and EHS (29.6\%) majors reported having no/low levels of HIV/AIDSrelated knowledge, whereas a significantly larger proportion of BS (32.4\%) majors reported being completely knowledgeable $\left(\chi^{2}=24.78, P<0.001\right)$.

\section{HIV/AIDS-RELATED INFLUENCES AND CONSEQUENCES}

Table 3 contains comparisons by academic major of the extent to which participants' believed certain factors influence contracting HIV. On average (using a scale from 1 to 10), participants believed behavioral factors have the most influence on contracting HIV $(M=7.49 \pm 3.68)$, followed by social factors $(M=6.70 \pm 3.70)$, genetic factors $(M=4.18 \pm 3.99)$, environmental factors $(M=3.87 \pm 3.52)$, and spiritual factors $(M=1.72 \pm 2.85)$. No significant mean differences were observed by STEM status. However, post hoc examinations of mean differences by secondary academic major group revealed $\mathrm{HK}$ participants believed behavioral factors had significantly more influence on a person contracting HIV relative to their PMEB counterparts $(f=3.85, P=0.010)$. HK participants also believed 


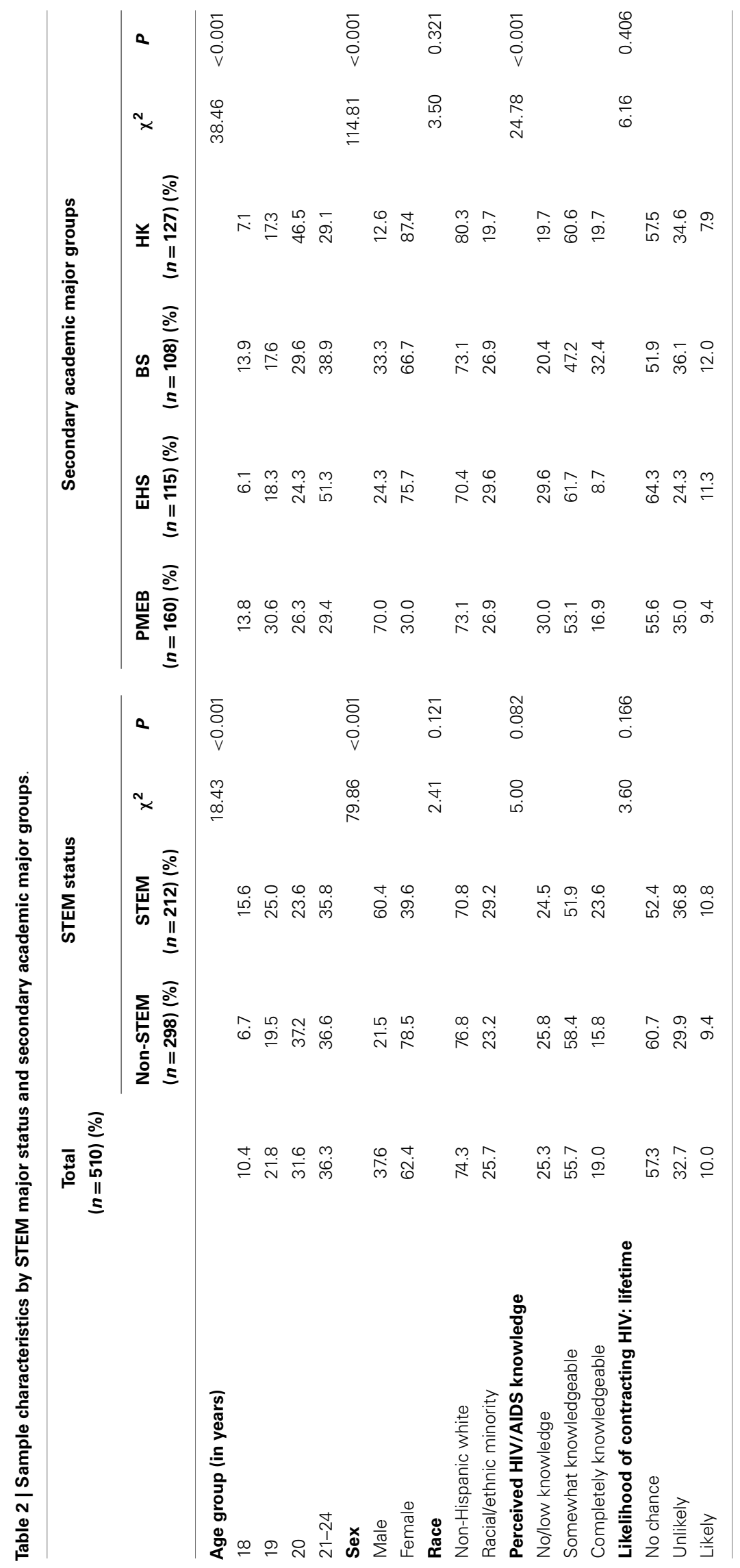


environmental factors had significantly more influence on a person contracting HIV relative to their EHS counterparts $(f=2.78$, $P=0.041)$.

Table 3 also contains comparisons, by academic major, of the extent to which participants' perceived contracting HIV would be detrimental to various aspects of their life. On average (using a scale from 1 to 7 ), participants perceived contracting HIV would be most detrimental to their quality of life $(M=6.20 \pm 1.22)$, followed by their physical well-being $(M=6.17 \pm 1.27)$, social life $(M=5.99 \pm 1.37)$, mental well-being $(M=5.92 \pm 1.42)$, emotional well-being $(M=5.89 \pm 1.47)$, and spiritual well-being $(M=4.52 \pm 2.16)$. When compared by STEM status, STEM majors perceived contracting HIV would be significantly less detrimental to their mental well-being $(t=2.40, P=0.017)$, emotional well-being $(t=2.11, P=0.036)$, and spiritual well-being $(t=3.03, P=0.003$ ) compared to their non-STEM counterparts. Post hoc examinations of mean differences by secondary academic major group revealed HK participants perceived contracting HIV would be significantly more detrimental to their social lives $(f=3.45, P=0.017)$, mental well-being $(f=4.36, P=0.005)$, and spiritual well-being $(f=4.45, P=0.004)$ compared to their PMEB counterparts, respectively. HK and BS participants perceived contracting HIV would be more detrimental to their emotional wellbeing relative to PMEB majors, respectively $(f=4.86, P=0.002)$.

\section{HIV/AIDS-RELATED FACTORS ASSOCIATED WITH ACADEMIC MAJOR}

Table 4 displays the results of the binary logistic regression analysis that examined sociodemographics and HIV-related factors associated with academic majors by STEM status (non-STEM served as the referent group). Participants who were female $(\mathrm{OR}=0.17$, $P<0.001)$ and those who believed contracting HIV would be detrimental to their spiritual well-being $(\mathrm{OR}=0.87, P=0.015)$ were statistically significantly less likely to be STEM majors.

Table 5 displays the results of the multinomial logistic regression analysis that examined sociodemographics and HIV-related factors associated with secondary academic major group (HK majors served as the referent group). The first model compared PMEB majors to HK majors. Relative to $\mathrm{HK}$ majors, participants who were 20 years of age $(\mathrm{OR}=0.24, P=0.006), 20-24$ years of age $(\mathrm{OR}=0.35, P=0.047)$, female $(\mathrm{OR}=0.05, P<0.001)$, and completely knowledgeable about HIV/AIDS (OR $=0.41$, $P=0.047$ ) were statistically significantly less likely to be PMEB majors. Compared to HK majors, PMEB majors were statistically significantly less likely to believe behavioral factors influenced a person contracting $\mathrm{HIV}(\mathrm{OR}=0.86, P=0.004)$. Compared to $\mathrm{HK}$ majors, those who believed contracting HIV would be detrimental to their quality of life were statistically significantly more likely to be STEM majors $(\mathrm{OR}=2.14, P=0.012)$; whereas, those who believed contracting HIV would be detrimental to their mental well-being were statistically significantly less likely to be STEM majors $(\mathrm{OR}=0.58, P=0.042)$.

The second model compared EHS majors to HK majors. Relative to HK majors, female participants $(\mathrm{OR}=0.46, P=0.036)$ and participants who self-reported to be "completely knowledgeable" about HIV/AIDS (OR $=0.25, P=0.004)$ were significantly less likely to be EHS majors than HK majors. The third model compared BS majors to HK majors. Relative to HK majors, participants

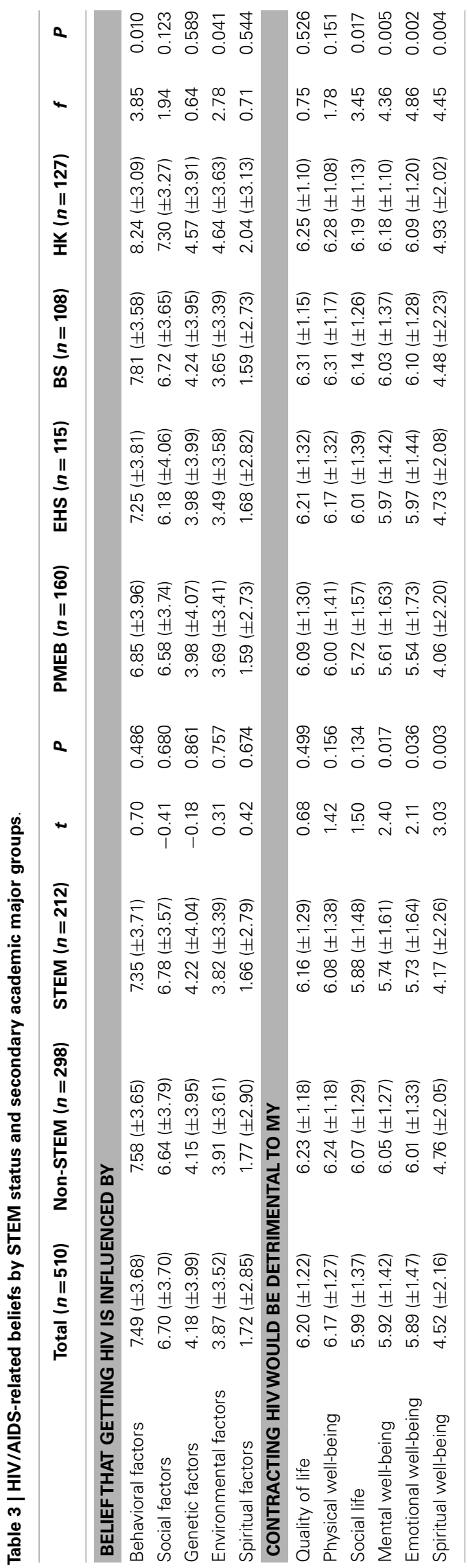


Table 4 | Factors associated with STEM academic majors

\begin{tabular}{|c|c|c|c|c|}
\hline & \multirow[b]{2}{*}{ OR } & \multirow[b]{2}{*}{$\boldsymbol{P}$} & \multicolumn{2}{|c|}{$95 \% \mathrm{Cl}$} \\
\hline & & & Lower & Upper \\
\hline Age: 18 years & 1.00 & - & - & - \\
\hline Age: 19 years & 3.13 & 0.001 & 1.55 & 6.33 \\
\hline Age: 20 years & 1.40 & 0.222 & 0.82 & 2.41 \\
\hline Age: $21-24$ years & 0.73 & 0.210 & 0.44 & 1.20 \\
\hline Male & 1.00 & - & - & - \\
\hline Female & 0.17 & $<0.001$ & 0.11 & 0.27 \\
\hline Non-Hispanic white & 1.00 & - & - & - \\
\hline Racial/ethnic minority & 1.30 & 0.285 & 0.81 & 2.09 \\
\hline HIV knowledge: no/low & 1.00 & - & - & - \\
\hline HIV knowledge: somewhat & 0.69 & 0.238 & 0.37 & 1.28 \\
\hline HIV knowledge: completely & 0.71 & 0.205 & 0.42 & 1.21 \\
\hline HIV lifetime risk: no chance & 1.00 & - & - & - \\
\hline HIV lifetime risk: unlikely & 0.81 & 0.545 & 0.40 & 1.62 \\
\hline HIV lifetime risk: likely & 1.31 & 0.466 & 0.63 & 2.73 \\
\hline Behavioral factors as HIV risk & 0.96 & 0.297 & 0.90 & 1.03 \\
\hline Social factors as HIV risk & 1.04 & 0.285 & 0.97 & 1.12 \\
\hline Genetic factors as HIV risk & 1.03 & 0.256 & 0.98 & 1.10 \\
\hline Environmental factors as HIV risk & 0.98 & 0.632 & 0.91 & 1.06 \\
\hline Spiritual factors as HIV risk & 0.97 & 0.483 & 0.90 & 1.05 \\
\hline Detrimental: quality of life & 1.33 & 0.164 & 0.89 & 2.00 \\
\hline Detrimental: physical well-being & 0.96 & 0.858 & 0.65 & 1.44 \\
\hline Detrimental: social life & 1.02 & 0.900 & 0.78 & 1.33 \\
\hline Detrimental: mental well-being & 0.84 & 0.295 & 0.60 & 1.17 \\
\hline Detrimental: emotional well-being & 1.09 & 0.587 & 0.80 & 1.48 \\
\hline Detrimental: spiritual well-being & 0.87 & 0.015 & 0.78 & 0.97 \\
\hline
\end{tabular}

Referent group: non-stem majors.

who were 20 years of age $(\mathrm{OR}=0.29, P=0.013)$ and female $(\mathrm{OR}=0.31, P=0.001)$ were significantly less likely to be $\mathrm{BS}$ majors.

\section{DISCUSSION}

As previously noted, analyses of relationships between students' majors and numerous characteristics and patterns are prevalent in published research. However, there is a paucity of research examining relationships between students' majors and their health behaviors, health knowledge, and perceptions regarding chronic diseases; especially examining relationships of STEM and nonSTEM majors with health concepts. To date, perceptions about HIV/AIDS have yet to be examined in relation to academic major. Although college students report high levels of knowledge about the HIV/AIDS epidemic, previous studies have shown many misconceptions about this condition persisting among undergraduate students (23-26). To complement and augment the prior research, the authors of this study utilized an instrument based on the health belief model to examine how HIV/AIDS-related knowledge, perceived risk, and perceived consequences differed by academic major among students enrolled in a Texas university. The findings confirmed the existence of variation pertaining to HIV-related factors by academic major within this cohort.

While high school students are strongly encouraged to select STEM majors upon entry into college to achieve academic success and subsequent vocational opportunities, their exposure to formal health-related education and associated content is inherently limited. As such, when comparing factors related to HIV/AIDS-related knowledge, perceived risk, and perceived consequences, it seems plausible that STEM majors would be significantly different from non-STEM majors in a variety of ways. However, findings from the current study revealed only few significant differences based on STEM status, thus warranting our reclassification into four secondary academic major groups. This reclassification enabled us to compare HIV/AIDS-related factors by more practically grouped academic categories, based on curricula similarities and exposure to health-related content.

As hypothesized, the responses of HK majors significantly differed from other majors, especially PMEB majors. While further research is needed to fully understand the nuances of these differences, we offer possible interpretations of these findings below. HK majors reported being more knowledgeable about HIV/AIDS compared to their counterparts enrolled in other majors. Perceived differences in HIV/AIDS-related knowledge by major may reflect the nature of the HK major, which comprise an array of healthrelated course requirements and electives (e.g., community health, human sexuality, health disparities, and epidemiology). By tailoring the design and delivery of course content, instructors may present HIV/AIDS-related content pertaining to prevalence and incidence rates, modes of transmission, and risk and protective factors.

In terms of factors influencing HIV/AIDS transmission, PMEB majors perceived behavioral factors to have less influence on contracting HIV/AIDS, when compared to HK majors. One possible interpretation for this finding may be that PMEB majors perceive their future employment opportunities to have less risk for being exposed to HIV/AIDS, unlike their HK counterparts who frequently enter allied health professions (e.g., nursing) where exposure to blood-borne pathogens may exist as an inherent occupational risk. This finding may also indicate that PMEB majors have not been exposed to HIV/AIDS-related education and are either naive about modes of HIV transmission or embrace historical stereotypes that HIV/AIDS is only an issue among those of lower socioeconomic status, intravenous drug users, or men who have sex with men.

Health and kinesiology majors reported contracting HIV would be more detrimental to their lives (e.g., mental well-being, social life, emotional well-being, and spiritual well-being) relative to their counterparts from other majors. This finding begs to question whether HK majors truly know and understand more about the realities of living with HIV/AIDS and thus have more accurate perceptions of the risks and ramifications of the disease. The realization of the negative impacts of living with HIV may be associated with being educated about the balance among the dimensions of health (e.g., physical, mental, emotional, social, spiritual, vocational) $(27,28)$, which are necessary to be considered healthy (i.e., beyond the mere absence of physical illness) (29). Conversely, considering HIV is increasingly considered a "chronic condition" (30-32), it seems feasible to believe HK majors would also be aware of the various mechanisms that exist to alleviate burdens associated with HIV/AIDS. Further, HK students, compared to PMEB students, may be more familiar with the well-documented relationships between spirituality and 


\begin{tabular}{|c|c|c|c|c|c|c|c|c|c|c|c|c|}
\hline & \multicolumn{4}{|c|}{ PMEB } & \multicolumn{4}{|c|}{ EHS } & \multicolumn{4}{|c|}{ BS } \\
\hline & \multirow[b]{2}{*}{ OR } & \multirow[b]{2}{*}{$P$} & \multicolumn{2}{|c|}{$95 \% \mathrm{Cl}$} & \multirow[b]{2}{*}{ OR } & \multirow[b]{2}{*}{$P$} & \multicolumn{2}{|c|}{$95 \% \mathrm{Cl}$} & \multirow[b]{2}{*}{ OR } & \multirow[b]{2}{*}{$P$} & \multicolumn{2}{|c|}{$95 \% \mathrm{Cl}$} \\
\hline & & & Lower & Upper & & & Lower & Upper & & & Lower & Upper \\
\hline Age: $21-24$ years & 0.35 & 0.047 & 0.13 & 0.99 & 2.05 & 0.212 & 0.66 & 6.31 & 0.57 & 0.259 & 0.21 & 1.52 \\
\hline Age: 20 years & 0.24 & 0.006 & 0.09 & 0.66 & 0.58 & 0.353 & 0.19 & 1.82 & 0.29 & 0.013 & 0.11 & 0.77 \\
\hline Age: 19 years & 0.71 & 0.523 & 0.24 & 2.05 & 1.03 & 0.962 & 0.31 & 3.44 & 0.49 & 0.193 & 0.17 & 1.44 \\
\hline Age: 18 years & 1.00 & - & - & - & 1.00 & - & - & - & 1.00 & - & - & - \\
\hline Female & 0.05 & $<0.001$ & 0.03 & 0.11 & 0.46 & 0.036 & 0.22 & 0.95 & 0.31 & 0.001 & 0.15 & 0.63 \\
\hline Male & 1.00 & - & - & - & 1.00 & - & - & - & 1.00 & - & - & - \\
\hline Racial/ethnic minority & 1.05 & 0.883 & 0.53 & 2.08 & 1.45 & 0.266 & 0.75 & 2.79 & 1.38 & 0.344 & 0.71 & 2.71 \\
\hline Non-Hispanic white & 1.00 & - & - & - & 1.00 & - & - & - & 1.00 & - & - & - \\
\hline HIV knowledge: completely & 0.41 & 0.047 & 0.17 & 0.99 & 0.25 & 0.004 & 0.09 & 0.64 & 1.38 & 0.444 & 0.61 & 3.16 \\
\hline HIV knowledge: somewhat & 0.60 & 0.138 & 0.30 & 1.18 & 0.64 & 0.171 & 0.33 & 1.22 & 0.72 & 0.372 & 0.36 & 1.47 \\
\hline HIV knowledge: no/low & 1.00 & - & - & - & 1.00 & - & - & - & 1.00 & - & - & - \\
\hline HIV lifetime risk: likely & 1.19 & 0.747 & 0.42 & 3.33 & 1.29 & 0.606 & 0.49 & 3.45 & 2.12 & 0.131 & 0.80 & 5.65 \\
\hline HIV lifetime risk: unlikely & 1.20 & 0.570 & 0.64 & 2.23 & 0.69 & 0.245 & 0.37 & 1.29 & 1.43 & 0.243 & 0.78 & 2.62 \\
\hline HIV lifetime risk: no chance & 1.00 & - & - & - & 1.00 & - & - & - & 1.00 & - & - & - \\
\hline Behavioral factors as HIV risk & 0.86 & 0.004 & 0.78 & 0.95 & 0.94 & 0.203 & 0.85 & 1.04 & 0.94 & 0.228 & 0.85 & 1.04 \\
\hline Social factors as HIV risk & 1.05 & 0.401 & 0.94 & 1.16 & 0.98 & 0.663 & 0.88 & 1.08 & 1.01 & 0.790 & 0.92 & 1.12 \\
\hline Genetic factors as HIV risk & 1.03 & 0.490 & 0.95 & 1.12 & 1.03 & 0.512 & 0.95 & 1.11 & 1.03 & 0.395 & 0.96 & 1.12 \\
\hline Environmental factors as HIV risk & 0.95 & 0.336 & 0.86 & 1.05 & 0.93 & 0.169 & 0.84 & 1.03 & 0.91 & 0.070 & 0.83 & 1.01 \\
\hline Spiritual factors as HIV risk & 0.94 & 0.266 & 0.84 & 1.05 & 0.99 & 0.865 & 0.89 & 1.10 & 0.98 & 0.746 & 0.88 & 1.09 \\
\hline Detrimental: quality of life & 2.14 & 0.012 & 1.18 & 3.88 & 1.65 & 0.099 & 0.91 & 2.99 & 1.21 & 0.556 & 0.65 & 2.25 \\
\hline Detrimental: physical well-being & 1.15 & 0.650 & 0.63 & 2.09 & 0.96 & 0.907 & 0.52 & 1.78 & 1.41 & 0.274 & 0.76 & 2.59 \\
\hline Detrimental: social life & 0.80 & 0.260 & 0.54 & 1.18 & 0.87 & 0.523 & 0.58 & 1.32 & 0.91 & 0.662 & 0.60 & 1.39 \\
\hline Detrimental: mental well-being & 0.58 & 0.042 & 0.34 & 0.98 & 0.68 & 0.178 & 0.39 & 1.19 & 0.58 & 0.051 & 0.34 & 1.00 \\
\hline Detrimental: emotional well-being & 1.15 & 0.506 & 0.76 & 1.75 & 1.17 & 0.476 & 0.76 & 1.81 & 1.45 & 0.117 & 0.91 & 2.29 \\
\hline Detrimental: spiritual well-being & 0.87 & 0.084 & 0.75 & 1.02 & 1.00 & 0.955 & 0.85 & 1.16 & 0.89 & 0.105 & 0.76 & 1.03 \\
\hline
\end{tabular}

Referent group: HK majors.

overall health status among individuals with chronic conditions $(33,34)$.

This study is not without limitations. The questionnaire used to collect data from participants was not specifically designed for the purposes of this study, thus it did not include items measuring actual HIV-related risk (e.g., being sexually active, using condoms or other barrier methods, using intravenous drugs, working in an environment with an elevated risk of needle-sticks), knowledge about modes of HIV transmission, or clinical consequences of getting HIV/AIDS (e.g., opportunistic infection, mortality). While the close-ended and Likert-type scales included in the instrument were useful to initially assess participants' perceptions of HIV-related risk, severity, and consequences, future studies should include open-ended items or a qualitative inquiry (e.g., interviews, focus groups) to further investigate the sources of HIV knowledge as well as information/drivers about perceived risk and consequences. Such a qualitative study would be beneficial to professionals when developing educational and behavior change interventions in university settings. Additionally, the instrument did not include items regarding participants' K-12 sexuality education experiences or if they ever took a human sexuality course at the college level. Further, the majority of sample participants were over
19 years of age, thus their HIV/AIDS-related knowledge, views, and beliefs may have differed from their younger counterparts who recently enrolled in the university setting. Data were self-reported and drawn from a convenience sample, thus biases associated with social desirability and self-selection may exist. Further, data were cross-sectional in nature and collected from students at one college campus, thus findings may not be representative of other college student populations and should not be widely generalized beyond this study sample. To build upon these findings, future studies should be conducted across a larger number of college campuses of varying sizes. Such studies could include colleges that widely offer and have high enrollment in human sexuality courses and examine the level of education (or exposure to content) needed to influence students' sexual behavior and HIV/AIDS-related perceptions.

Although this study did not collect information pertaining to students' enrollment in human sexuality courses, further research is needed to determine if exposure to basic health education content has potential to increase HIV/AIDS-related knowledge and perceptions about causal factors and ramifications. From the college administration perspective, strategies can be employed to increase all students' exposure to sexuality content despite academic major. For example, to increase college students' exposure 
to HIV/AIDS-related content in formal education settings, college curricula may be modified to require human sexuality as a mandated core course, or component of a core course, for graduation. Such formal education requirements may take the form of freshman seminars or one-credit courses. However, informal sexuality education mechanisms are often available on college campuses to complement sexuality education efforts offered in formal settings. Examples of informal education may utilize the reach of student health organizations to provide peer sexuality education in a variety of settings (e.g., dormitories, fraternities/sororities, other university-sanctioned organizations) to positively impact student knowledge and perceptions about HIV/AIDS-related issues (35). Peer education for health promotion interventions has the potential to help reduce risky sexual behaviors among college students by increasing their knowledge and self-efficacy for condom-use, refusing sexual intercourse and negotiating safer practices with a partner (36).

The observed correlation between exposure to sexuality content and perceived knowledge about sexual risk-taking behaviors may have implications that transcend formal curricula modification and informal peer sexuality education. Within this discussion, we must also consider sexuality education through a larger lens that encompasses experiences during primary and secondary schooling. When a college student enrolls in and attends their first semester on a university campus, they bring a vast range of preconceived attitudes and beliefs as well as a predefined level of knowledge about sex and HIV/AIDS. Therefore, depending on the level of sexuality education received prior to college enrollment, students' sexual health competency and ability to protect themselves from contracting sexually transmitted infections (or preventing unplanned pregnancies) inherently differs. If students are not required to receive sexuality education through their college curricula, the expectation for these individuals to protect themselves and their classmates from negative sexuality-related ramifications can only be dictated from other sources including family, friends, or the media, which may not relay accurate or credible information (37-39). To complement educational efforts, evidence suggests the effectiveness of group-based behavioral interventions to encourage protective behaviors, reduce risk-taking activities, and prevent disease transmission (40). Such interventions have potential for integration in existing healthy sexuality initiatives on college campuses and can be facilitated by university health clinics or other campus-affiliated entities.

\section{CONCLUSION}

The content, timing, and delivery mechanisms of sex education and HIV education are hotly debated topics within the United States' K-12 system yet largely ignored or downplayed in the higher education system. These discrepancies are largely attributed to variation in regulations from state-to-state and district-to-district, which dictate and restrict sexuality education curricula and sexual health content delivered in the classroom (41). These inconsistencies have potential to deprive young adults from obtaining the necessary sexual health information needed to protect themselves from STI and foster engagement in risky behavior once students discover the freedoms inherent to many college experiences. The reasons associated with differences in knowledge and perceptions about HIV/AIDS risk and consequences across undergraduate majors are relatively unexplored and deserve more attention. If we gain a better understanding of these issues, we can better inform the formal college/university core curriculum and informal oncampus interventions related to HIV/AIDS, to increase knowledge and skills among college students who likely have not and will not be exposed to sexuality education in their academic coursework. Without a focus on such activities, communication about this topic may never occur. Overall, undergraduates have a wide variety of knowledge and skills about HIV/AIDS. This paper recommends further study to explore what type of education and support students with various majors need in order to understand the risk and prevention of HIV/AIDS. Students enter and progress through their undergraduate education with highly varied levels of knowledge related to general sexual health and consequences associated with risky sexual behavior $(42,43)$. Human sexuality is rarely mandated for graduation on college campuses; however, certain majors offer such courses through required courses or electives (44). Thus, students in health-focused academic majors have an added opportunity for exposure to human sexuality education or HIV/AIDS prevention. Additionally, sexuality topics may be incorporated in courses with a different primary focus of the course (e.g., program planning, interventions, program evaluation, epidemiology, community health).

Consequently, some fields of study may never include HIV/AIDS-related education in a formal setting. Thus, these students may have less knowledge about risk factors, disease transmission, as well as health and social ramifications of certain sexual behaviors. To public health professionals who have participated in professional preparation that included healthy sexuality and safe sex, these behaviors may seem common sense, but for a young adult who has not encountered the information may not comprehend their risk levels. The ramifications of human sexuality research cross academic discipline lines yet the human sexuality discussions are still relegated to health departments and student health care clinics.

\section{AUTHOR CONTRIBUTIONS}

Matthew Lee Smith designed the study, collected the data, performed data analyses, conceptualized the study, and wrote portions of the manuscript. Lisa L. La Place, Mindy Menn, and Kelly L. Wilson conceptualized the study and wrote portions of the manuscript.

\section{REFERENCES}

1. Warren K. HPV knowledge among female college students and the short term effectiveness of HPV education. Internet J Acad Phys Assist (2010) 7(2):14. Available from: http://ispub.com/IJAPA/7/2/9260

2. Caldeira KM, Arria AM, Zarate EM, Vincent KB, Wish ED, O'Grady KE. Prospective associations between alcohol and drug consumption and risky sex among female college students. J Alcohol Drug Educ (2009) 53(2):71-92.

3. Lewis JE, Miguez-Burbano MJ, Malow RM. HIV risk behavior among college students in the United States. Coll Stud J (2009) 43(2):475-91.

4. Patrick ME, Morgan N, Maggs JL, Lefkowitz ES. 'I got your back': friends' understandings regarding college student spring break behavior. J Youth Adolesc (2011) 40(1):108-20. doi:10.1007/s10964-010-9515-8

5. Rhodes SD, McCoy TP, Wilkin AM, Wolfson M. Behavioral risk disparities in a random sample of self-identifying gay and non-gay male university students. $J$ Homosex (2009) 56(8):1083-100. doi:10.1080/00918360903275500 
6. Schwartz SJ, Waterman AS, Vazsonyi AT, Zamboanga BL, Whitbourne SK, Weisskirch RS, et al. The association of well-being with health risk behaviors in college-attending young adults. Appl Dev Sci (2011) 15(1):20-36. doi:10.1080/ 10888691.2011.538617

7. Beggs JM, Bantham JH, Taylor S. Distinguishing the factors influencing college students' choice of major. Coll Stud J (2008) 42(2):381-94.

8. García-Aracil A. College major and the gender earnings gap: a multi-country examination of postgraduate labour market outcomes. Res High Educ (2008) 49(8):733-57. doi:10.1007/s11162-008-9102-y

9. Lichtenstein G, McCormick AC, Sheppard SD, Puma J. Comparing the undergraduate experience of engineers to all other majors: significant differences are programmatic. J Eng Educ (2010) 99(4):305-17. doi:10.1002/j.2168-9830.2010. tb01065.x

10. Robst J, VanGilder J. Functional impairment and the choice of college major. East Econ J (2010) 36(2):164-76. doi:10.1057/eej.2008.62

11. Schneider RG, Ross SR, Fisher M. Academic clustering and major selection of intercollegiate student-athletes. Coll Stud J (2010) 44(1):64-70.

12. Breiner JM, Johnson CC, Harkness SS, Koehler CM. What is STEM? A discussion about conceptions of STEM in education and partnerships. Sch Sci Math (2012) 112(1):3-11. doi:10.1111/j.1949-8594.2011.00109.x

13. Espinosa LL. Pipelines and pathways: women of color in undergraduate STEM majors and the college experiences that contribute to persistence. Harv Educ Rev (2011) 81(2):209-41.

14. Griffith AL. Persistence of women and minorities in STEM field majors: is it the school that matters? Econ Educ Rev (2010) 29(6):911-22. doi:10.1016/j. econedurev.2010.06.010

15. Major DA, Holland JM, Oborn KL. The influence of proactive personality and coping on commitment to STEM majors. Career Development Quarterly (2012) 60(1):16-24. doi:10.1002/j.2161-0045.2012.00002.x

16. Thompson R, Bolin G. Indicators of success in STEM majors: a cohort study. Journal of College Admission (2011) 212:18-24.

17. Whalen DF, Shelley MC. Academic success for STEM and non-STEM majors. Journal of STEM Education: Innovations and Research (2010) 11(1-2): 45-60.

18. Smith ML. Learning by doing: preparing the next generation of health education researchers. Eta Sigma Gamma Student Monogr (2008) 25(3):55-60.

19. Smith ML, Dickerson JB, Sosa ET, J McKyer EL, Ory MG. College students' perceived disease risk versus actual prevalence rates. Am J Health Behav (2012) 36(1):96-106. doi:10.5993/AJHB.36.1.10

20. Smith ML, Sosa ET, Hochhalter AK, Covin J, Ory MG, McKyer ELJ. Correlates of family health history discussions between college students and physicians: does family cancer history make a difference? J Prim Prev (2011) 32(5-6):311-22. doi:10.1007/s10935-011-0246-8

21. Smith ML, Sosa ET, Tisone CA, McKyer ELJ. Quality enhancement groups: a qualitative research method for survey instrument development. J Health Behav Public Health (2011) 1(1):15-22. Available from: http://www.asciencejournal. net/asj/index.php/HBPH/article/viewArticle/207

22. Rosenstock IM. Social learning theory and the health belief model. Health Educ Behav (1988) 15(2):175-83. doi:10.1177/109019818801500203

23. Inungu J, Mumford V, Younis M, Langford S. HIV Knowledge, attitudes, and practices among college students in the United States. J Health Hum Serv Adm (2009) 32(3):259-77.

24. Hightow LB, MacDonald PD, Pilcher CD, Kaplan AH, Foust E, Nguyen TQ, et al. The unexpected movement of the HIV epidemic in the Southeastern United States: transmission among college students. JAcquir Immune Defic Syndr (2005) 38(5):531-7. doi:10.1097/01.qai.0000155037.10628.cb

25. Opt SK, Loffredo DA. College students and HIV/AIDS: more insights on knowledge, testing, and sexual practices. Journal of Psychology. (2004) 138(5):389-402. doi:10.3200/JRLP.138.5.389-403

26. Opt SK, Loffredo DA, Knowles L, Fletcher C. College students and HIV/AIDS: a comparison of nontraditional and traditional student perspectives. J Am Coll Health (2007) 56(2):165-74. doi:10.3200/JACH.56.2.165-174

27. Anspaugh D, Hamrick M, Rosato F. Wellness: Concepts and Applications. 6th ed. Boston, MA: McGraw Hill (2004).

28. Hales D. An Invitation to Health. 11th ed. Belmont, CA: Thomson \& Wadsworth (2005).

29. World Health Organization. Preamble to the Constitution of the World Health Organization as Adopted by the International Health Conference. New York, NY: United Nations (1946).
30. Barlow J, Wright C, Sheasby J, Turner A, Hainsworth J. Self-management approaches for people with chronic conditions: a review. Patient Educ Couns (2002) 48(2):177. doi:10.1016/S0738-3991(02)00032-0

31. Clarke A. What is a chronic disease? The effects of a re-definition in HIV and AIDS. Soc Sci Med (1994) 39(4):591-7. doi:10.1016/0277-9536(94)90102-3

32. Epping-Jordan JE, Pruitt SD, Bengoa R, Wagner EH. Improving the quality of health care for chronic conditions. Qual Saf Health Care (2004) 13(4):299-305. doi:10.1136/qshc.2004.010744

33. Harvey I, Silverman M. The role of spirituality in the self-management of chronic illness among older African and Whites. J Cross Cult Gerontol (2007) 22(2):205-20. doi:10.1007/s10823-007-9038-2

34. Nichols LM, Hunt B. The significance of spirituality for individuals with chronic illness: implications for mental health counseling. J Ment Health Couns (2011) 33(1):51-66.

35. Smith ML, Menn M, Dorsett L, Hugill-Warren L. Sex in the dark: a program to address college students' questions about sexuality. J Health Behav Public Health (2012) 2(1):1-9. Available from: http://www.asciencejournal.net/asj/index.php/ HBPH/article/viewArticle/260

36. Bulduk S, Erdogan S. The effects of peer education on reduction of the $\mathrm{HIV} /$ sexually transmitted infection risk behaviors among Turkish university students. J Assoc Nurses AIDS Care (2012) 23(3):233-43. doi:10.1016/j.jana.2011. 02.003

37. Jones RK, Biddlecom AE, Hebert L, Mellor R. Teens reflect on their sources of contraceptive information. J Adolesc Res (2011) 26(4):423-46. doi:10.1177/ 0743558411400908

38. Lagus KA, Bernat DH, Bearinger LH, Resnick MD, Eisenberg ME. Parental perspectives on sources of sex information for young people. JAdolesc Health (2011) 49(1):87-9. doi:10.1016/j.jadohealth.2010.10.007

39. Rojas-Guyler L, King KA. Sexuality education among latinas: experiences, preferences, attitudes and risk behavior. Am J Sex Educ (2007) 2(4):25-41. doi: 10.1300/J455v02n04-03

40. Community Preventive Services Task Force. Recommendations for group-based behavioral interventions to prevent adolescent pregnancy, human immunodeficiency virus, and other sexually transmitted infections: comprehensive risk reduction and abstinence education. Am J Prev Med (2012) 42(3):304-7. doi:10.1016/j.amepre.2011.11.003

41. Synovitz I, Herbert E, Kelly RM, Carlson G. Sexual knowledge of college students in a southern state. American Journal of Health Studies. (2002) 17(4):163-73.

42. Hoff T, Greene L, Davis J. National Survey of Adolescents and Young Adults: Sexual Health Knowledge, Attitudes and Experiences. Washington, DC: The Henry J. Kaiser Family Foundation (2003).

43. Sutton MJ, Brown JD, Wilson KM, Klein JD. Shaking the tree of knowledge for forbidden fruit: where adolescents learn about sexuality and contraception. In: Brown JD, Steele JR, Walsh-Childers K, editors. Sexual Teens, Sexual Media: Investigating Media's Influence on Adolescent Sexuality. Mahwah, NJ: Lawrence Erlbaum Associates Publishers (2002). p. 25-55.

44. American College Health Association. ACHA Guidelines: Standards for Practice for Health Promotion in Higher Education 2. (2005) [cited 2011 Nov 1]. Available from: http://www.acha.org/Publications/docs/Standards $\% 20$ of $\%$ 20Practice\%20for\%20Health\%20Promotion\%20in\%20Higher\%20Education Jan2005.pdf

Conflict of Interest Statement: The authors declare that the research was conducted in the absence of any commercial or financial relationships that could be construed as a potential conflict of interest.

Received: 10 October 2013; accepted: 20 February 2014; published online: 12 March 2014.

Citation: Smith ML, La Place LL, Menn M and Wilson KL (2014) HIV-related knowledge and perceptions by academic major: implications for university interventions. Front. Public Health 2:18. doi: 10.3389/fpubh.2014.00018

This article was submitted to Public Health Education and Promotion, a section of the journal Frontiers in Public Health.

Copyright (C) 2014 Smith, La Place, Menn and Wilson. This is an open-access article distributed under the terms of the Creative Commons Attribution License (CC BY). The use, distribution or reproduction in other forums is permitted, provided the original author(s) or licensor are credited and that the original publication in this journal is cited, in accordance with accepted academic practice. No use, distribution or reproduction is permitted which does not comply with these terms. 